\title{
Review of Data Provision to the Fund for Surveillance Purposes
}




\section{INTERNATIONAL MONETARY FUND}

\section{Review of Data Provision to the Fund for Surveillance Purposes}

\section{Prepared by the Policy Development and Review and Statistics Departments}

In consultation with other Departments

Approved by Mark Allen and Robert W. Edwards

March 17, 2008

Contents

List of Acronyms.

I. Introduction

II. Trends in Data Provision.........................................................................................

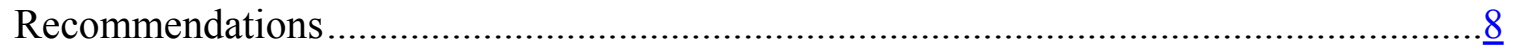

III. Treatment of Data Issues in Surveillance .................................................................

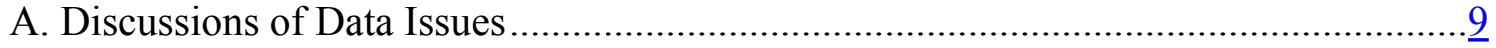

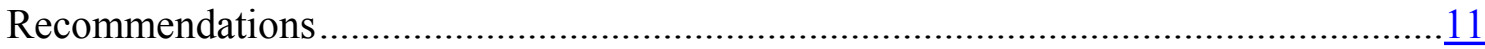

B. Handling of Potential Breaches of Article VIII, Section 5 ..................................13

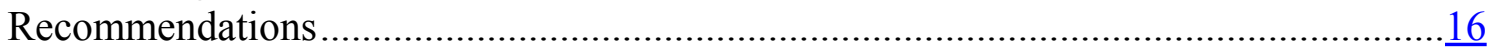

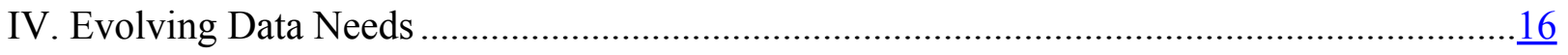

A. Positions and Exposures vis-à-vis the Rest of the World .....................................16

B. Intersectoral Positions and Exposures.........................................................

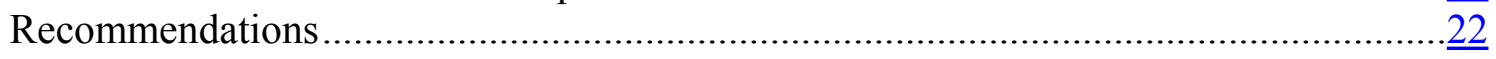

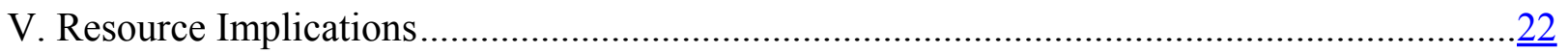

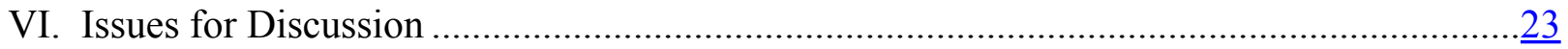

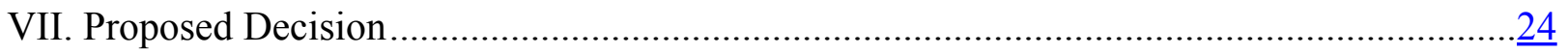

Appendix

I. Review of Treatment of Data Issues in Staff Reports .................................................27

II. Background Information on the Review of Handling of Potential Breaches of Article VIII, Section 5 
Box 1. Follow-up on IEO Finding that Members' Unwillingness to Provide Data Frequently Hinders Exchange Rate Analysis $\underline{14}$

Table 1. Coverage of Standardized Report Forms .$\underline{26}$

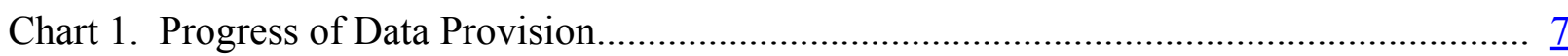




\section{LIST OF ACRONYMS}

$\begin{array}{ll}\text { BOPCOM } & \text { Committee on Balance of Payments Statistics } \\ \text { BOPSY } & \text { Balance of Payments Statistics Yearbook } \\ \text { BPM6 } & \text { Balance of Payments Manual (sixth edition) } \\ \text { BSA } & \text { Balance Sheet Approach } \\ \text { CCE } & \text { Coordinated Compilation Exercise } \\ \text { CDIS } & \text { Coordinated Direct Investment Survey } \\ \text { COFER } & \text { Currency Composition of Official Foreign Exchange Reserves } \\ \text { CPIS } & \text { Coordinated Portfolio Investment Survey } \\ \text { FDI } & \text { Foreign Direct Investment } \\ \text { FSAP } & \text { Financial Sector Assessment Program } \\ \text { FSI } & \text { Financial Soundness Indicators } \\ \text { GDDS } & \text { General Data Dissemination System } \\ \text { IEO } & \text { Independent Evaluation Office } \\ \text { IIP } & \text { International Investment Position } \\ \text { MFSM } & \text { Monetary and Financial Statistics Manual } \\ \text { ROSC } & \text { Report on the Observance of Standards and Codes } \\ \text { SDDS } & \text { Special Data Dissemination Standard } \\ \text { SDRF } & \text { Supplementary Data Report Form } \\ \text { SIA } & \text { Statistical Issues Appendix } \\ \text { STA } & \text { Statistics Department } \\ \text { SRF } & \text { Standardized Report Form } \\ \text { SWF } & \text { Sovereign Wealth Fund } \\ \text { TA } & \text { Technical Assistance } \\ \text { TCIRS } & \text { Table of Common Indicators Required for Surveillance } \\ & \end{array}$




\section{INTRODUCTION}

1. Data are crucial for surveillance, and the Fund thus keeps data provision by members under periodic review. Providing the data the Fund needs to exercise surveillance is one of the most basic undertakings associated with Fund membership. This access to data is, in turn, a pillar of the value added of surveillance. The present review of data provision follows important changes in the data provision framework approved at the time of the 2004 review and the Board's 2004 Decision on Strengthening the Effectiveness of Article VIII, Section $5 .^{12}$

2. The policy framework for data provision to the Fund is centered on the Articles of Agreement and relies on a cooperative approach:

- $\quad$ Article VIII, Section 5, together with the Board's 2004 Decision, defines a set of data categories that members are required to provide to the Fund, for surveillance and other activities (Annex I). ${ }^{3}$ These data are considered to be the minimum necessary for surveillance. The requirement to provide them is subject to the varying capacity of members: surveillance is impaired when a member is unable to provide these data (with acceptable quality), but an issue of observance of Article VIII, Section 5 arises only if a member has the requisite capacity yet does not do so.

- $\quad$ Fund surveillance (bilateral or multilateral) may entail additional data requirements, which vary according to members' individual circumstances and over time. In practice, the Fund has not formally required a member to furnish additional information; nonetheless, most members provide extensive data to the Fund that far exceed the data specifically required under Article VIII, Section 5.

- Monitoring of data provision by members is anchored on a Table of Common Indicators Required for Surveillance (TCIRS), reported to the Board in the context of Article IV consultations. The TCIRS summarizes information on the periodicity and timeliness of most of the core indicators required by Article VIII, Section 5 and

\footnotetext{
${ }^{1}$ See Review of Data Provision to the Fund for Surveillance Purposes ( 2/24/04) and PIN No. 04/37; 4/12/04/04, and IMF Decisiion No. 13183-(04/10), 1/30/2004. Unless noted otherwise, all documents cited in this paper are available at www.imf.org.

${ }^{2}$ The review was prepared by a team led by Tessa van der Willigen (PDR) and J. R. Rosales (STA), and comprising Lynn Aylward, Isabelle Mateos y Lago, Pedro Rodriguez, and Yan Sun (all PDR) and John Cady, Jesus Gonzalez-Garcia, Mico Mrkaic, and Gerardo Peraza (all STA).

${ }^{3}$ Article IV, Section 3(b), under which members must provide the Fund with the information necessary for surveillance over exchange rate policies, is another legal basis for data provision.
} 
the 2004 Decision (Annex II). Where a data module of a Report on the Observance of Standards and Codes (ROSC) has been published, the TCIRS includes (since January 2005) data quality ratings for five macroeconomic datasets.

- In the context of Article IV consultations, staff is enjoined to assess the adequacy of data provided to the Fund, the implications of data inadequacies, and the scope for improvement. Detailed guidance is provided to staff for this purpose.

- Where staff is concerned that a member is failing to provide data (or to provide accurate data) to the Fund, despite having the capacity to do so, procedures for follow-up are defined in the Board's 2004 Decision. These procedures rely importantly on a cooperative approach.

- In addition, of course, and outside the framework of data provision by members, the Fund collects data from other sources, such as other international organizations and private sector providers - including (often very high-frequency) data of special importance to financial sector surveillance, such as asset prices and market-based risk indicators.

3. This paper reviews how well members are providing the data the Fund needs, how well staff is handling issues of data inadequacy, and how the Fund's data needs are evolving. The aim is to identify possible ways of improving data provision or, where data provision can only improve as the result of protracted capacity building, to ensure that surveillance takes due account of data inadequacies.

4. The backward-looking discussion is based on: (i) a review of the TCIRS in the 144 Article IV staff reports discussed by the Executive Board between October 2006September 2007 (Annex III); (ii) a review of a sample of 50 of these reports (see Annex IV for sample selection) and follow-up interviews with a subset of country teams; (iii) a survey of mission chiefs (Annex V); and (iv) a review of cases where staff have had concerns about observance of Article VIII, Section 5.

5. It is proposed that reviews of the data listed in the 2004 Decision henceforth be conducted together with reviews of data provision to the Fund. The present paper discusses developments in data provision and in the Fund's data needs, and thus inevitably touches on whether the list of data in the annex to the 2004 Decision remains appropriate. It is thus proposed that, with the discussion of this paper, the Board also conclude the review of the list of data defined in the 2004 Decision, required to take place by end-2009, and that subsequent reviews of this list be conducted together with the review of data provision. These reviews are scheduled to take place on an "as needed" basis, which generally means at an interval of at least five years, and it is proposed that the next reviews be conducted in 2013 unless a need arises earlier. 


\section{Trends in Data Provision}

\section{Findings}

6. The adequacy of data for surveillance remains an issue in many countries. Close to half of staff reports note data deficiencies - albeit of varying seriousness - that affect surveillance. Just over half of the mission chiefs who responded to the survey noted problems in timely provision of data or severe deficiencies in key data, with 40 percent of these reporting that the team routinely prepares estimates for some key data, with estimation based on limited indicators. ${ }^{4}$ These orders of magnitude are consistent with a finding of the IEO Report on Evaluation of IMF Exchange Rate Policy Advice (5/17/07; available at www.ieoimf.org/), whereby about 40 percent of staff who responded to the IEO survey reported "better data availability" as a promising area to raise the overall quality of exchange rate analysis.

7. Staff reports' assessments of data adequacy suggest steady improvement in the last decade or so. Data provision was assessed to be adequate or broadly adequate for surveillance in 90 percent of the 50 Article IV consultations reviewed in detail, up from previous reviews (Chart 1). Assessments of data adequacy reached independently by reviewers based on the detailed information provided in the staff report (see paragraph 15) reached broadly similar results, although reviewers' assessments point to a smaller decline since 2003 in the number of "inadequate" cases. ${ }^{5}$

\footnotetext{
${ }^{4}$ The survey results should be treated with caution on account of the moderate response rate ( 34 percent), but the respondents reflected a broadly representative sample of the membership, if anything biased toward countries with better data adequacy.

5 The "broadly adequate" category was introduced in 2005 and may have drawn cases away from the "inadequate" category_-see also paragraph 15.
} 
Chart 1. Progress of Data Provision ${ }^{1}$

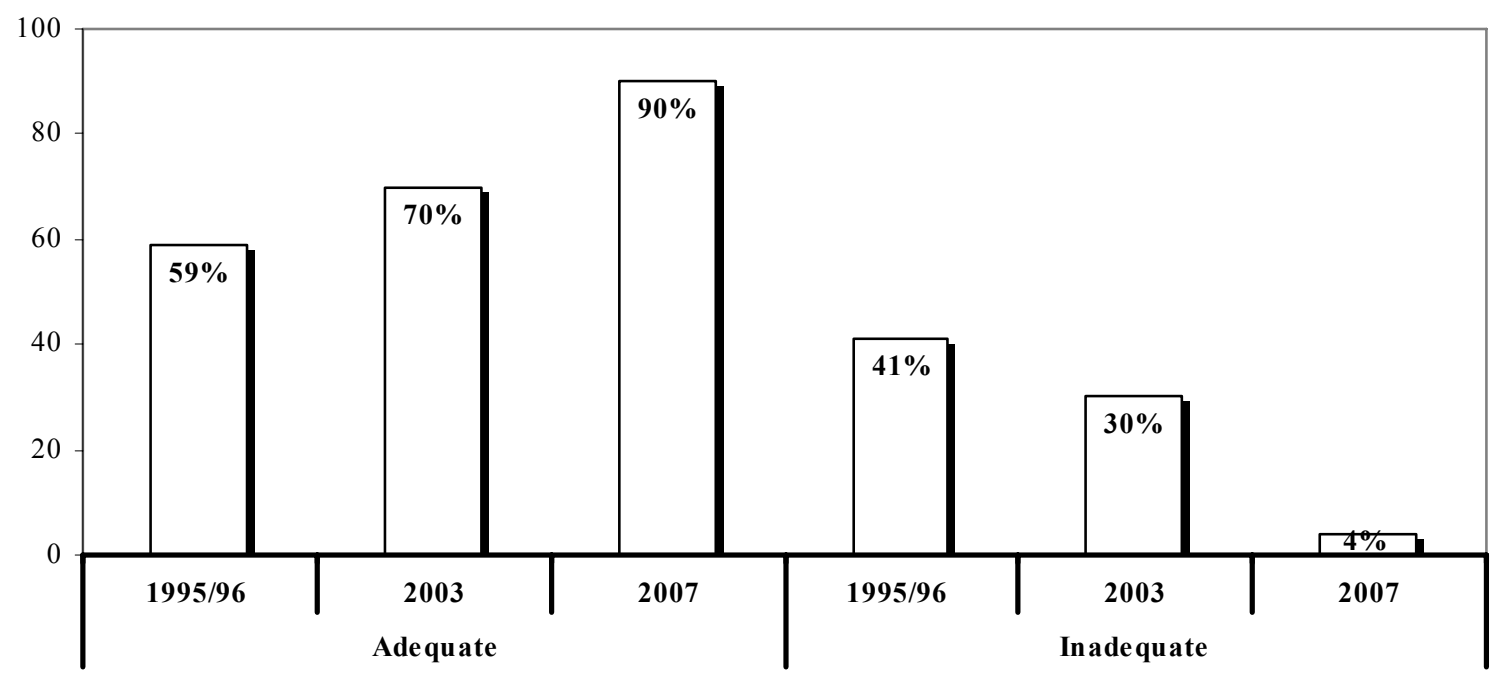

${ }^{1}$ For 2007, the "adequate" category also includes cases assessed as "broadly adequate," a category that was introduced in 2005. In addition, 6 percent of cases in 2007 do not have a clear assessment.

8. However, an analysis of the timeliness of data provision since 2004 suggests some slackening, perhaps related to the broadening of reporting requirements introduced at the time of the last review (Annex III). With the exception of the exchange rate (for which reporting is broadly unchanged), the share of countries providing high-frequency indicators within one month of the reference period has declined somewhat, probably reflecting in part more comprehensive definition of some data categories (such as reserves). For lowfrequency indicators, data on government finance and external trade statistics are now defined with a broader scope than in 2004, and the shares of countries reporting these data within two quarters declined by around 8 percentage points, while timeliness for indicators with unchanged definitions has remained broadly similar.

\section{Overall, progress appears to have been greatest in developing countries without} market access, which also retain the greatest scope for improvement. Staff assessments of the adequacy of data provision suggest that 80 percent of developing countries without market access provide adequate or broadly adequate data (up from 61 percent in the 2004 review). But countries whose data are assessed to be inadequate for surveillance are primarily low income or small countries - including post-conflict cases - that have serious capacity constraints. ${ }^{6}$ Similarly, the review of TCIRS-based timeliness in reporting suggests

\footnotetext{
${ }^{6}$ Similar findings have been reported in the context of the Fund's General Data Dissemination System.
} 
that, as in the last review, countries with low per capita GDP and small populations have the greatest scope for improvement.

10. The greatest challenges in the provision of key macroeconomic data are in national accounts, external, and fiscal data. These categories were identified as the main areas with deficiencies in the review of TCIRS reporting, the review of staff reports, and the survey of mission chiefs. Similarly, in the 61 cases where the TCIRS included data ROSC quality ratings, the national accounts and fiscal data were the least likely categories to observe international standards for methodological soundness, and accuracy and reliability.

\section{Overall, the findings suggest that further progress in data provision will hinge} primarily on increases in capacity in developing countries. While the Fund has supported such effort through its technical assistance (TA), experience suggests that key impediments to statistical capacity building include scarcity of resources, low priority assigned to statistical development, and insufficient ownership of TA recommendations. ${ }^{7}$

\section{Recommendations}

12. The Fund, in concert with the rest of the international community, can continue to support countries' capacity building through TA and other means:

- $\quad$ Better prioritization and delivery of technical assistance, as called for in the Fund's re-focusing efforts, within the constraints of a shrinking budget.

- As proposed in the recent informal Executive Board seminar on reforming the General Data Dissemination System (GDDS) (FO/DIS/08/5), the upcoming seventh review of data standards will seek to emphasize the dissemination of the data included in the TCIRS, as an impetus for better data provision.

- In addition, in its discussions with donors on their support to individual countries and on their aid policies more generally, the Fund can emphasize the importance of providing targeted support for strengthening countries' statistical capacity. This would be consistent with the growing focus on managing for development results as a pillar of aid effectiveness, and with the associated rise in the use of outcome-based conditions for donor support.

\footnotetext{
${ }^{7}$ See IEO Evaluation of the Technical Assistance Provided by the International Monetary Fund, January 31, 2005; available at http://www.ieo-imf.org/.
} 


\section{Treatment OF DATa ISSUES IN SURVEILlanCE}

13. Effective surveillance requires candid and diligent treatment of data issuesfirst, for the sake of the integrity of staff's analysis and advice, which may be subject to significant uncertainty when based on inadequate data; and second, because such treatment is an essential first step in any remedial strategy. Concerns have been previously raised with regard to both candor and diligence:

- $\quad$ The 2004 review of data provision found scope for sharper assessments in staff reports of data adequacy and its implications. The present review revisits this issue by examining the treatment of data issues in the sample of 50 staff reports, against the background of the evidence from the mission chief survey.

- $\quad$ The 2003 paper on strengthening the effectiveness of Article VIII, Section 5 and the IEO evaluation of exchange rate policy advice, in turn, suggested that there was not always adequate follow-up in cases where members were unwilling to provide information. The present review seeks to update and refine these findings, in light of the strengthened procedures adopted in 2004, by examining cases where staff had concerns - or should have had concerns_-about a member's observance of Article VIII, Section 5.

\section{A. Discussions of Data Issues}

\section{Specific guidance exists on the treatment of data issues in staff reports, to assist} the staff in the conduct of consultation discussions and help ensure that the reasonable expectations of the audiences of staff reports are met, while also clarifying where these issues do not need discussion in reports. The guidance was revised following the 2004 review. This section examines both the implementation and appropriateness of this guidance, including in light of the objective of streamlining staff reports as part of the re-focusing of the Fund, based on the review of the sample of 50 staff reports and the mission chief survey (Appendix I elaborates).

\section{Findings}

15. Staff reports are expected to contain a summary assessment of data adequacy, but the findings suggest that these statements are not always candid and consistent across countries:

- Under current guidance, data provision is expected to be classified into one of three categories: "adequate for surveillance," "still adequate overall, but with shortcomings that affect staff"s analysis of some key issues" (hereafter "broadly adequate"), or "inadequate for surveillance." The intent of the required assessment is to promote a candid rendering of data weaknesses, and to identify cases where the consultation must pay attention to the weaknesses and their implications for analysis. 
- $\quad$ The findings suggest some upward bias in characterizations of data adequacy. Most staff reports assess appropriately the adequacy of data provision, but a minority of assessments appear to be more positive than warranted or insufficiently clear. Consistently, it is difficult to reconcile the very infrequent description of data as "inadequate" with the large number of mission chiefs who report concerns about key data gaps or serious deficiencies (paragraph 6). Reasons for a bias likely include the following:

$>$ Mission teams typically expend considerable effort responding to data deficiencies by preparing estimates and ensuring data consistency, and may base their statements about data adequacy on the estimates that result from this effort.

Mission chiefs (as indicated by the survey) are concerned that the term "inadequate" may give rise to questions about how surveillance can be conducted at all where data are inadequate for it.

16. Where data are found to be "inadequate" or "broadly adequate," staff reports are expected to include a discussion of data issues-but the findings suggest that existing guidance calls for too much in cases where data issues are relatively minor (and as a result has not been consistently implemented), and that it delivers too little where data issues really matter:

- $\quad$ For the cases characterized as either inadequate or broadly adequate, current guidance calls for the main text of the staff report to (i) specify those data weaknesses that significantly affect staff's analysis, (ii) highlight their implications for the analysis, and (iii) where relevant indicate remedial measures and recommendations.

- In practice, implementation of this guidance has been uneven. Discussion of implications of data deficiencies for surveillance is absent (or limited to noting that "data weaknesses hamper surveillance") in about three quarters of the relevant cases; and discussion of remedial measures is missing in a third of the relevant cases (and partial and generic in many of the rest). In addition, staff reports typically give little sense of the authorities' response to staff's suggestions for remedial measures.

- Uneven implementation of the guidance may indicate that it is overambitious. This is especially so as, with the "inadequate" category used infrequently, the "broadly adequate" category has included countries with data shortcomings ranging from relatively minor to severe:

$>$ At the high end of this range, staff reports may not need to discuss data issues at all; 
In the middle, the reader needs a sense of the uncertainties involved in assessing the state of the economy and framing policy conclusions, but an indepth discussion of remedial measures with the authorities may not be needed;

At the low end, data problems are a serious economic policy issue and an appropriate focus of surveillance. In these cases, not only does the staff report need to convey a sense of the uncertainties affecting its analysis, but in-depth engagement with the authorities on remedial measures is needed as a means to data improvement (including to support the effectiveness of technical assistance, through greater ownership by the authorities and better prioritization by the Fund).

\section{The review found room for improving the focus and coverage of the statistical} issues appendix (SIA), that, along with the TCIRS, must be included in staff reports. SIAs (since January 2007 typically issued in electronic form only) have provided adequate details on data issues in the traditional sectors (real, fiscal, monetary, external). But discussions do not necessarily mirror the severity of the issues, including their implications for surveillance, often offering information on issues with secondary significance. In addition, SIAs typically lack coverage of financial sector data issues (beyond a focus on monetary statistics).

\section{Finally, the review found that Executive Board discussions of Article IV} consultations pay relatively little attention to data issues. In cases where data provision was not considered fully adequate, relatively few summings up referred to data concerns (and sometimes only implicitly). Better engagement from the Board on data issues could help focus the authorities on their importance and provide impetus for more rigorous follow up.

\section{Recommendations}

19. Accordingly — taking into account the need for parsimony and streamlining of staff reports as part of the re-focusing of the Fund-staff recommends:

- $\quad$ Keeping a classification system to help staff think through what is required in the consultation, but eliminating the "inadequate" characterization and using the following categories:

A. Data provision is adequate for surveillance.

B. Data provision has some shortcomings, but is broadly adequate for surveillance.

C. Data provision has serious shortcomings that significantly hamper surveillance.

Adequacy should be judged based on the aggregate impact of shortcomings in coverage, periodicity, timeliness, and other aspects of quality, on the staff's ability to analyze the key economic issues and draw policy conclusions. Key to the distinction 
between cases $\mathrm{B}$ and $\mathrm{C}$ would be a judgment as to whether data deficiencies have introduced significant uncertainty into the policy conclusions. ${ }^{8}$

- $\quad$ Limiting the expectation for discussion in the main text of the staff report to case $\mathrm{C}$ countries. (Of course, discussion could also be included in other cases if the team considers it useful.) For case $\mathrm{C}$ countries:

$>$ The main text of the staff report (and similarly the SIA) should note the nature of the deficiencies (coverage, periodicity, timeliness, or other aspects of data quality). Where there has been extensive estimation of historical data, this should be noted, with tables and charts clearly indicating figures that are the staff's estimates rather than (pre-existing) official data.

$>$ The main text of the staff report should highlight the implications of the data shortcomings for the analysis, in particular policy conclusions that are subject to significant uncertainties.

$>$ In cases where staff have had to construct key data based on limited information (either because of lack of, or long lags in, official data), the main text of the staff report should propose specific and prioritized remedial measures and report on the discussion with the authorities.

Consideration should be given to including data issues, as relevant, in the staff appraisal, which would also help elicit appropriate focus on them in the Board discussion.

- $\quad$ Area department teams should ensure that the SIA is properly focused on data shortcomings that have significant implications for surveillance (e.g., with a prominent summary that highlights such areas upfront). The SIA should also be expanded to cover financial sector data issues when warranted, and where applicable, use information from FSAPs.

\footnotetext{
${ }^{8}$ Cases where data deficiencies could result in significant uncertainty could include, for example, large discrepancies between the fiscal balance and its financing that cast doubt on the fiscal stance; insufficient coverage of key exports or imports and private flows, resulting in large errors or omissions in the balance of payments that make it difficult to assess external sustainability; severe weaknesses in price statistics (e.g. choice of weights) that hinder assessment of inflation; and poor national accounts data (e.g. limited coverage, outdated base year for constant price GDP) that hinder analysis of economic activity.
} 


\section{B. Handling of Potential Breaches of Article VIII, Section 5}

\section{Findings}

20. Between the review of such cases in 2003 and September 2007, eleven members are known to have elicited sustained concerns about their willingness to share data required for Fund surveillance to the best of their ability. ${ }^{9}$ These cases involved data specifically required under Article VIII, Section 5, with concerns related to non-reporting, late reporting, or inaccurate reporting for a variety of data. Nine of these cases were the subject of interdepartmental discussion during the review period. Two additional cases, which were not discussed among departments, were identified as part of a follow-up on the IEO's finding that 23 percent of country teams experienced unwillingness of members to share data/information critical/relevant to exchange rate analysis (see Box 1). ${ }^{10}$

21. Just over half these cases have been resolved, though with a sometimes very slow process. Out of the eleven cases, six have been resolved - three in about a year, but three after many years. Some ongoing cases have been active for over two years.

\section{Staff's efforts to address potential breaches of Article VIII, Section 5 follow good practice in many ways, albeit with large variance (Appendix II):}

- On the positive side, concerns typically begin to be addressed quickly, and in most cases staff engages the authorities promptly, and with reasonably quick follow-up. ${ }^{11}$ There is also evidence of learning from experience, e.g. in flagging potential Article VIII, Section 5 cases when non-provision of data raises issues of observance of both the SDDS and Article VIII, Section 5.

\footnotetext{
${ }^{9}$ In addition, over the same period, 16 cases of misreporting under a Fund arrangement concerned data required under Article VIII, Section 5. These cases are not further considered in this review, as all were addressed through the misreporting guidelines, which have their own more stringent procedures and deadlines, related to the possible need for repurchases. In 13 of these cases, the misreporting incidents were not considered to raise concerns of possible breach of Article VIII, Section 5; in the three cases where findings of breach of Article VIII, Section 5 were made by the Board, this primarily reflected the fact that provision of inaccurate data on a performance criterion automatically constitutes a breach of Article VIII, Section 5- not a concern that data required for surveillance purposes had been misreported.

${ }^{10}$ The review team also researched press reports from major news outlets for the period January 2005 to September 2007 for potential problems in the provision or reporting of data specified within Article VIII, Section 5 that may have escaped staff's attention. This review did not find additional potential cases.

${ }^{11}$ Indeed, during the period under review there were also two cases - not included in the discussion abovewhere staff became concerned about a potential breach of Article VIII, Section 5, but determined quickly, in consultation with the authorities, that there was in reality no cause for concern.
} 


\section{Box 1. Follow up on IEO Finding that Members' Unwillingness to Provide Data Frequently Hinders Exchange Rate Analysis}

The IEO's Evaluation of the IMF's Exchange Rate Policy Advice found that 23 percent of country teams had experienced unwillingness of members to share data/information critical to exchange rate analysisclearly a worrisome finding. The present review sought to explore in more detail what kinds of events were captured in this result.

In view of the confidentiality assured by the IEO to participants in its survey, the follow up could not target the respondents that accounted for the IEO's result. Instead, evidence was sought on the present review's 50-country sample, both from staff reports (October 2006-September 2007) and from a survey by the Monetary and Capital Markets Department (MCM) of country desks, focusing on key information needed for exchange regime classification and on other (Article VIII, Section 5) data relevant to exchange rate analysis. That survey focused on desks' current experience, with follow-up interviews conducted with country desks conducted with assurances of confidentiality.

In eight cases (16 percent of the sample), staff revealed concerns that a member was or had been unwilling to share data relevant for exchange rate analysis - a finding broadly consistent with the IEO survey, especially considering the latter's longer time frame (1999-2005):

- Of most concern was the fact that, out of four cases involving data explicitly required under Article VIII, Section 5, only two had been brought to interdepartmental debate, with concerns about the other cases not shared outside the country teams - although the teams had made repeated efforts to obtain the missing data. ${ }^{1 /}$ These cases are considered further in the text.

- Two cases related to non-provision of information rather than data (e.g., on the exchange arrangement and intervention tactics), and hence — while still worrisome- lie outside the scope of this review.

- Finally, two cases involved unwillingness to provide data not explicitly required under Article VIII, Section 5, but that staff considered relevant for exchange rate surveillance-specifically, intervention data. Both cases, however, were resolved quickly when staff explained their need for these data. Moreover, if pressed, staff may well have stopped short of calling these data necessary (rather than merely relevant). Indeed, non-provision of intervention data is relatively common, and interviews with staff suggest that in most cases they do not consider this to be a problem (and indeed do not request the data), because available reserves data are a reasonable proxy over anything but the very short run. This position seems generally appropriate, but there will be cases where the very short run is key to analyzing the authorities' policy framework, and where staff needs intervention data to support its analysis of exchange rate and monetary policies. The forthcoming MCM paper on classification of de facto exchange rate regimes will further examine these issues.

1/ Of the two cases brought to interdepartmental debate, one was related to misreporting under an arrangement, and the other was among the nine known cases discussed in paragraph 22. 
- However, there were also cases where staff could have been more resolute. Action was sometimes brought about by the need to take the Article IV consultation to the Board (implying sizable delays in cases of 24-month cycles). As noted above, in two cases, staff's concerns about authorities' reluctance to provide required data were not communicated to reviewing departments.

- All the cases remained in the stage (set out in the 2004 Decision) of preliminary consultation with the member, and none reached the stage where the Managing Director notifies the member of his intention to inform the Board of breach of obligations (referred to as the "letter stage" below). The fact that the "letter stage" was not reached seems more appropriate in cases of concerns about late or inaccurate reporting (where it takes some time to establish whether a problem exists) than in the cases of non-reporting (where the problem is evident and what needs to be established is only whether it is due to capacity constraints).

\section{The Executive Board is generally apprised of data gaps, but not always of a}

possible cooperation problem. Reporting to the Board generally occurs in the context of Article IV consultations. Its form varies, however: it can involve an explicit mention of a possible breach of Article VIII, Section 5, ${ }^{12}$ an implicit mention in the form of a reference to a cooperation problem, or a mere mention of data gaps with no allusion to unwillingness to share data. In general, staff prefers not to put forward suspicions it cannot prove, while discussions with the member continue. Related concerns seem to underlie delays in moving to the "letter stage."

\section{In two cases, issues arose in the interpretation of the "understandings" on the data under Article VIII, Section 5, and a pragmatic approach hinging on internationally accepted good practice proved workable. Data provision under} Article VIII, Section 5 is required to be "accurate" (within the limits of the member's capacity) by the standards of the applicable understandings, which can be either specifically agreed between the staff and the authorities, or "general," notably, derived from internationally accepted practices as embedded in compilation manuals (Annex VI). In practice, staff typically has informal "specific" understandings with authorities on the definitions and compilation methods of many data, but it is very difficult for such understandings to cover all the detail of all the data required for surveillance. Fortunately, the two cases in the sample where the issue of understandings arose suggest that a pragmatic approach relying on the commonly understood meaning of terms as described in the compilation manuals is workable in cases where there are no relevant specific understandings between staff and the member.

12 Under the 2004 Decision, when the Managing Director is of the view that a member is in breach of Article VIII, Section 5, he shall make a report to the Executive Board. 


\section{Recommendations}

25. Overall, the review suggests that the approach followed by staff sometimes reflects a delicate tradeoff, but that there is scope for moving the process forward more expeditiously in some cases. To promote consistent and evenhanded treatment across members, staff recommends clarifying guidance to staff regarding the steps to follow when there is a question that a member may not be complying with Article VIII, Section 5:

- These steps should include seeking clarification from the authorities; enlisting the cooperation of the Executive Director; and engaging with the authorities at the management level. These steps should be taken as a continuum, without unwarranted breaks between them.

- In cases of non-provision of data, the "letter stage" should follow promptly. In cases of late or inaccurate reporting, there should be a plan and timetable for moving to the "letter stage."

\section{EVolving Data NeEds}

26. The Fund remains engaged in major data initiatives focused on the assessment of positions (i.e., stocks) and related exposures of key sectors of the economy. These initiatives had their origin in the lessons of the crises of the 1990s, and have paid particular attention to both positions and exposures across domestic sectors and vis-à-vis the rest of the world. Many of these initiatives are of special importance to countries with well-developed financial systems, while more traditional data needs remain key in less advanced countries (see paragraphs 9-11). The initiatives and data needs have acquired new prominence in light of recent developments in the world economy - in particular global imbalances and the credit market turmoil. Overall, newly-emerging data needs reinforce the importance of positions data and associated measures of vulnerabilities, suggesting that top priority should remain on moving current initiatives forward, rather than creating new ones. Other important ongoing data initiatives are discussed in Annex VII.

\section{A. Positions and Exposures vis-à-vis the Rest of the World}

\section{Measuring positions and exposures vis-à-vis the rest of the world is key to} surveillance in two respects. First, it allows an assessment of how vulnerable a country may be to specific external sector developments. Second, it sheds light on potential spillovers that developments in one country can have on other countries.

\section{International Investment Position (IIP)}

28. Assessing developments in countries' IIPs has become more important for Fund surveillance. Both global imbalances and the 2007 Decision on Surveillance (through its emphasis, inter alia, on the sustainability of current account positions) have shone a spotlight on developments in countries' net foreign assets as a key component of national and international stability. Data needs in this area cover a wide range: 
- $\quad$ Expand country coverage: In spite of the progress achieved in recent years, over 70 economies do not yet report IIP data for the Balance of Payments Statistics Yearbook (BOPSY).

- Improve valuation of Foreign Direct Investment (FDI). Valuation of FDI has been highlighted as a key element to understand movements in countries' IIPs. ${ }^{13}$ Nevertheless, the issue remains poorly understood.

- Improve understanding of exchange rate-related valuation changes in countries' IIP, particularly through the introduction of currency breakdowns in IIPs. Currency breakdowns provide an indication of potential wealth effects associated with exchange rate movements and, therefore, constitute an important element of balance sheet vulnerabilities (or strengths).

- $\quad$ Measure the geographic breakdown of positions, which would be a useful tool for the analysis of spillovers.

29. To help address these needs, the Fund is undertaking several initiatives to improve the measurement of countries' IIPs. The sixth edition of the Balance of Payments Manual (BPM6), currently under preparation, will provide more detailed guidance on measuring IIPs, and when the Balance of Payments Statistics Yearbook (BOPSY) converts to BPM6, it will include both new world tables (which will help identify potential measurement problems across IIP components) and supplementary tables capturing the currency breakdown of IIPs. In addition, the Fund is pursuing a strategy to expand the number of countries publishing IIP data, with efforts focused on a small group of countries that evolves as IIP data are published. Also, the Fund is to conduct a Coordinated Direct Investment Survey (CDIS), which will yield information on FDI positions by counterpart economy, and could help improve FDI valuation. The CDIS is also expected to complement the Coordinated Portfolio Investment Survey (CPIS) as a tool to analyze geographical breakdown of IIP positions. There is strong international interest in these initiatives, and many are being undertaken with the support of the IMF Committee on Balance of Payments Statistics (BOPCOM).

\section{Consideration should be given to incorporating IIP data into the TCIRS in} Article IV reports. IIP is a key data category in Article VIII, Section 5 but is not in the TCIRS. Including it in the TCIRS would allow staff and the Board to track the provision of this key indicator more closely. The TCIRS would report on the frequency and timeliness of reporting of gross assets and liabilities. (Countries would of course continue to be encouraged to report according to the standard IIP tables, which provide detail.)

\footnotetext{
${ }^{13}$ See, e.g., the United States 2007 Article IV Consultation, Figure 8 (Country Report No. 07/264; 8/1/07).
} 


\section{Sovereign Wealth Funds}

\section{Sovereign Wealth Funds (SWFs) are becoming more prominent players in} international financial markets and more important for countries' external stability. Data on SWFs are important for several reasons. First, SWF data are an essential component of the country's IIP, which is needed to analyze the country's external stability. Second, the revenues associated with SWFs' assets may have an important impact on the country's fiscal situation (and thereby its domestic and external stability). Finally, SWF data may be important to the assessment of other countries' financial stability, particularly of those that are recipients of large inflows of capital invested by SWFs.

\section{Against this background, the Fund is undertaking several initiatives in the area} of SWF data, as part of a broader work program that also includes working with SWFs toward the preparation of a set of best practices. Efforts are underway to improve the coverage of SWFs in macroeconomic statistics and methodological guidance. In this context, the draft BPM6 includes a methodology to help countries determine whether or not SWFs' assets are to be presented as reserve assets and a voluntary additional data item on SWFs in the IIP. Additional data on SWFs, such as returns and asset composition and currency of denomination, and increased participation in relevant data initiatives (including the CPIS and the CDIS) would also be useful. However, these issues need to be considered further in the context of developing best practices and discussed with relevant statistical committees, including BOPCOM.

\section{Reserve Assets and Foreign Currency Liquidity}

\section{The reporting of international reserves and foreign currency liquidity has} significantly improved with the introduction of a reporting template (Reserves Template). The template - mandatory under the SDDS - has served since 2000 as the benchmark for the provision of data on reserves and foreign currency liquidity to the Fund. It thereby also serves - like other internationally accepted methodologies - as a general guide to interpretation of the data category "international reserve assets and reserve liabilities of the monetary authorities, specifying separately any reserve assets which are pledged or otherwise encumbered as well as net derivative positions" in the expanded list of data required under Article VIII, Section 5 (i.e., in Annex A of the 2004 Decision). 


\section{It would be desirable to establish greater consistency in the treatment of reserve} liabilities between the expanded list of Article VIII, Section 5 and the Reserves Template. ${ }^{14}$ The reference to reserve liabilities in Annex A captures only liabilities and derivatives settled in foreign currency, while the template recognizes the importance of liabilities and derivatives linked to the exchange rate but settled in domestic currency. As financial markets and intervention instruments continue to develop, it would be desirable to further align the coverage of Annex A with that of the template. In this context, staff proposes a revision in item (viii) of Annex A to:

"for the monetary authorities: international reserve assets (specifying separately any reserve assets that are pledged or otherwise encumbered), reserve liabilities, shortterm liabilities linked to a foreign currency but settled by other means, and the notional values of financial derivatives to pay and to receive foreign currency (including those linked to a foreign currency but settled by other means)."

It is expected that most countries that use domestic currency-settled instruments already report them to the Fund (including as SDDS subscribers), so this change should bring little added reporting burden; nevertheless, staff would propose that the change enter into effect for periods after December 31, 2008. ${ }^{1516}$

\section{Currency Composition of Official Foreign Exchange Reserves}

\section{More widespread reporting of the currency composition of reserves would be} very useful for global surveillance and surveillance of reserve currency countries. Notably, such data would facilitate the assessment of developments in the US dollar and other major currencies - including the degree to which these developments reflect changes in official holdings - as well as projections of demand for these currencies under different scenarios. Better data in this area would thus provide a substantially stronger basis for assessment of the risks associated with global imbalances. ${ }^{17}$ The Fund monitors the currency

\footnotetext{
${ }^{14}$ The concept of "reserve liabilities" in Annex A relates to the "drains" in Sections II and III of the Reserves Template, and should not be confused with the concept of (short and long-term) "reserve-related liabilities" proposed to be introduced in BPM6.

${ }^{15}$ The proposed decision (Section VII) has both definitions coexisting during 2009, when data relating to 2008 will be reported on the old basis (i.e., as some members will still be reporting information to the Fund for periods through end-2008) and data relating to 2009 on the new basis, before deletion of the old definition from the 2004 Decision as of end-2009.

${ }^{16}$ Staff plans to revisit the treatment in the Template of exchange-traded futures, including those settled in domestic currency, in the upcoming seventh review of data standards. Changes that may be proposed for the Template Guidelines would be consistent with the new definition envisaged for Annex A.

${ }^{17}$ The importance of COFER data was also noted in the IEO Report on Evaluation of IMF Exchange Rate Policy Advice, paragraph 27 (ibid).
} 
composition of reserves through its COFER initiative, in which it guarantees the confidentiality of individual country data (Annex VIII). Aggregates are used in surveillance and also published, providing an important public good: COFER is the only source of these data worldwide and is widely used by central banks, other international organizations, the private sector, and others - further underscoring its usefulness for economic analysis. At present, 120 countries report COFER data, up from 105 in 2004. However, the proportion of world reserves accounted by COFER data has fallen slightly over this period, to 64 percent. Wider reporting is important if these data are to play their envisaged role in global surveillance, and would impose a minimal cost on members. Fund staff and management will again approach member countries that are not yet providing information to COFER to encourage them to report on a voluntary and confidential basis.

\section{B. Intersectoral Positions and Exposures}

\section{The current international credit turmoil reinforces the need to assess}

intersectoral positions and exposures. The Fund has implemented in recent years comprehensive data initiatives that specifically target the positions of financial institutions vis-à-vis other sectors of the economy, and some risk characteristics associated with those positions. The current turmoil has underlined that the international financial system now transfers credit risk much more widely than in the past, on account of: (i) more sophisticated financial instruments (notably complex financial derivatives); (ii) deeper linkages between banks and other financial institutions (e.g., hedge funds) — which are usually less closely regulated and transparent than banks; and (iii) stronger liquidity and credit risk spillovers between different countries. In addition, the importance of data on nonfinancial corporations and households has become still clearer, as the positions of these sectors are key determinants of both the performance of the financial system and the outlook for the real economy. The remainder of this section reviews the Fund's existing data initiatives in these areas, and how they can be adapted to take account of these evolving data needs.

\section{Standardized Report Forms}

\section{Standardization of monetary statistics across a growing section of the} membership is contributing to improved high-frequency and timely monetary and financial sector data. Standardized Report Forms (SRFs) for these statistics were introduced in 2005-06 and allow improved sectorization, classification, and valuation, as well as richer detail in terms of currency composition, which facilitates construction of sectoral balance sheets. In addition, expanding coverage has brought clear benefits in the form of more accurate and reliable credit aggregates, including in major emerging markets (Annex IX). As of end-2007, 83 countries had instituted the more detailed reporting through SRFs for at least the major depository corporations (mainly the central bank and commercial banks).

Nevertheless, data gaps remain for many countries, particularly regarding the coverage of certain deposit-taking institutions and other financial corporations (such as investment funds, 
pension funds, insurance companies, hedge funds, and private equity financial holding corporations).

38. Immediate priorities are to continue expanding SRF reporting and coverage, and to expand the SRFs to include additional information for the assessment of financial sector stability:

- $\quad$ Even in countries that have adopted SRF reporting, there remains significant scope for increasing coverage of financial institutions (Table 1).

- An expansion of the SRFs to include other data relevant for financial sector surveillance (e.g., off-balance sheet data) would improve the measurement of intersectoral positions and exposures and the application of the balance sheet approach (BSA) (Annex IX). A second phase of SRF implementation is planned to be launched soon on a pilot basis, with Supplementary Data Report Forms (SDRFs) to gather detail for deposits, loans, and securities on (i) short vs. long term maturity; (ii) fixed vs. variable interest rates; and (iii) type of loan (commercial, consumer, mortgage, etc.). Also, data would include financial derivatives, loan commitments, and credit guarantees, and — going beyond balance sheet data—income statements.

- $\quad$ STA plans to provide guidance on compilation of SRFs through publication of a Compilation Guide for the Monetary and Financial Statistics Manual (MFSM) in April 2008.

39. Simultaneously, the Fund should maintain close contact with financial regulators, country authorities, and other international organizations, to secure access to relevant data collected through new initiatives, and to work towards harmonized data methodologies. Financial regulators are well placed to assess the key data needs and to negotiate with financial institutions any additional reporting burden, and-in the context of the recent credit market turmoil — have already agreed with financial sector institutions in some countries/areas on tackling key data shortcomings. It will also be important to improve the cross-country comparability of the data, including through harmonized methodologies.

\section{Financial Soundness Indicators}

40. In support of financial sector surveillance, STA will undertake in 2008 regular collection and dissemination of internationally comparable financial soundness indicators (FSIs). In November 2007, the Executive Board reviewed the experience with the voluntary Coordinated Compilation Exercise (CCE), in which 62 economies compiled the 12 core FSIs and as many of the 28 encouraged FSIs as possible, with 2005 as the reference 
date. ${ }^{18}$ The Board agreed on regular collection and dissemination of FSIs by the Fund, and the creation of a database that would be publicly available. Countries would be encouragedbut not required - to report FSIs to the Fund. Future efforts will be aimed at expanding country coverage and consideration could also be given, within the medium-term budgetary envelope, to further refining the list of FSIs. In this context, recent experience (including the current turmoil) suggests that priority should be given to expanding information on sectoral balance sheets - both to assess financial sector interlinkages and vulnerabilities, as well as the vulnerabilities of households and corporates (e.g., currency and maturity mismatches). In addition, the Board encouraged continued efforts by the IMF and other international agencies to harmonize the methodologies of data compilation and reporting.

\section{Recommendations}

41. There is continuity between the data needs that came to prominence after the crises of the 1990s and those that have emerged more recently. Current Fund data initiatives seem well suited to tackle both types: as noted, most of the data needs are being addressed through ongoing initiatives such as SRFs and FSIs. Accordingly, expanding country and sectoral coverage of existing initiatives should remain the top data priority in coming years.

42. Consistently, there have been no new developments that would suggest a need for radical changes to the data requirements of the Fund's framework for data provision, although staff proposes two changes:

- the addition of IIP data to the TCIRS, and

- $\quad$ a revision of the provision on reserve assets and reserve liabilities of the monetary authorities that is part of Annex A of Article VIII, Section 5 in order to ensure that this provision captures liabilities and derivatives settled in domestic currency.

\section{RESOURCE IMPLICATIONS}

43. The proposed modifications in the frameworks underpinning data provision to the Fund (paragraphs 19, 25, and 42) would be accommodated within the existing budget constraint. The narrowing of the focus in the assessment of data adequacy to cases where data shortcomings significantly hamper surveillance takes account of the need for parsimony and streamlining of staff reports as part of the refocusing of the Fund. Work to implement the enhanced provisions on handling Article VIII, Section 5 cases is not expected to exceed current levels significantly. Assisting provision of IIP data will require giving greater priority — within the existing resource envelope - to training and technical assistance

\footnotetext{
${ }^{18}$ Public Information Notice (PIN) No. 07/135, November 20, 2007
} 
to countries committed to compiling such data, including the supporting CDIS data. Additional resources to handle an increased flow of COFER data on a confidential basis are expected to be modest.

\section{ISSUES FOR DISCUSSION}

- Do Directors agree that data shortcomings in countries with low incomes and/or small populations remain a major concern, and that the Fund should seek to strengthen its contribution to building capacity in this area, including through its dialogue with donors and the use of other Fund initiatives such as the GDDS (paragraph 12)?

- Do Directors agree that the proposals in paragraph 19 would be helpful to ensure that Article IV consultations assess candidly the adequacy of data provision for surveillance, discuss the implications of data shortcomings where these have a significant impact on the analysis and policy conclusions, and discuss remedial measures in cases where shortcomings are severe?

- $\quad$ Do Directors agree that the Fund's cooperative approach to data provision should be maintained, but that there is scope for more consistent treatment by staff of cases where members may not be sharing data to the best of their ability (paragraph 25)?

- Do Directors agree that expanding country and sectoral coverage of existing initiatives to improve collection of position and exposure data should be the top data priority in coming years (paragraph 41)?

- $\quad$ Do Directors agree to (i) add IIP data to the TCIRS, (ii) revise the description of data on reserve assets and reserve liabilities of the monetary authorities that is part of Annex A of Article VIII, Section 5 in order to ensure that this description captures liabilities and derivatives settled in domestic currency (paragraph 42)? 


\section{Proposed DeCision}

The following decision, which may be adopted by a majority of the votes cast, is proposed for adoption by the Executive Board.

1. Decision No. 13183-(04/10) on Strengthening the Effectiveness of Article VIII, Section 5, adopted January 30, 2004, as amended, is hereby amended as follows:

(i) In paragraph 1 all of the language after "December 31, 2004" shall be deleted and replaced with the following:

“, except as provided in paragraphs 1(a)-(b). Reviews of Annex A shall be conducted together with reviews of data provision to the Fund for surveillance purposes, and the next review of Annex A and data provision to the Fund for surveillance purposes shall take place no later than April 30, 2013.

(a) Members shall not be required to provide the data specified in paragraph (viii) of Annex A with respect to the periods commencing after December 31, 2008.

(b) Members shall provide the data specified in paragraph (xiii) of Annex A for the periods commencing after December 31, 2008."

(ii) Annex A shall be amended as follows:

(a) the word "and" in paragraph (xi) shall be deleted; 
(b) the word "system." in paragraph (xii) shall be deleted and replaced with "system; and"; and

(c) a new paragraph (xiii) shall be added to read as follows:

"for the monetary authorities: international reserve assets (specifying separately any reserve assets that are pledged or otherwise encumbered), reserve liabilities, short-term liabilities linked to a foreign currency but settled by other means, and the notional values of financial derivatives to pay and to receive foreign currency (including those linked to a foreign currency but settled by other means).”.

2. With effect from December 31, 2009, Decision No. 13183-(04/10) shall be further amended as follows:

(a) in paragraph 1, paragraph 1 (a) shall be deleted and paragraph 1 (b) shall be renumbered as paragraph 1 (a), and the references to "paragraphs 1 (a) and (b)" and to “paragraph (xiii)" shall be replaced with "paragraph 1 (a)", and "paragraph (viii)" respectively".

(b) in Annex A, paragraph (viii) shall be deleted and paragraph (xiii) shall be renumbered as paragraph (viii), the word "and" shall be added at the end of paragraph (xi) and, at the end of paragraph (xii), "system; and" shall be replaced with "system.". 
Table 1. Coverage of Standardized Report Forms

(As of Decembeer 2007)

\begin{tabular}{|c|c|c|c|c|c|c|c|c|c|c|c|c|c|c|c|c|c|}
\hline \multirow[b]{4}{*}{ Number of Reporters } & \multirow{4}{*}{$\begin{array}{c}\text { Central } \\
\text { Bank }\end{array}$} & \multicolumn{16}{|c|}{ Standardized Report Forms } \\
\hline & & \multirow{2}{*}{\multicolumn{9}{|c|}{ Other Depository Corporations }} & \multicolumn{7}{|c|}{$\begin{array}{l}\text { Other Financial Corporations } \\
\end{array}$} \\
\hline & & & & & & & & & & & \multirow{2}{*}{$\begin{array}{r}\text { Insurance } \\
\text { Co. }\end{array}$} & \multirow{2}{*}{$\begin{array}{l}\text { Pension } \\
\text { Funds }\end{array}$} & \multirow[b]{2}{*}{$\begin{array}{c}\text { Investment } \\
\text { funds, other } \\
\text { than money } \\
\text { markets }\end{array}$} & \multirow{2}{*}{$\begin{array}{r}\text { Finance } \\
\text { Co. }\end{array}$} & \multirow[b]{2}{*}{$\begin{array}{r}\text { Special } \\
\text { purpose } \\
\text { entities } \\
4 /\end{array}$} & \multirow[b]{2}{*}{$\begin{array}{r}\text { Other } \\
\text { financial } \\
\text { intermediaries } \\
\text { /auxiliaries 5/ }\end{array}$} & \multirow{2}{*}{$\begin{array}{r}\text { Other } \\
6\end{array}$} \\
\hline & & \multirow{2}{*}{$\begin{array}{r}\text { Commercial } \\
18 \\
\end{array}$} & $\begin{array}{r}\text { Rural \& } \\
\text { Agricultural }\end{array}$ & $\begin{array}{r}\text { Other } \\
\text { Specialized } \\
\text { Banks 1/ }\end{array}$ & $\begin{array}{l}\text { Offshor } \\
\text { banks }\end{array}$ & & \multirow{2}{*}{$\begin{array}{r}\text { S\&Ls } \\
\begin{array}{r}\text { Building So. } \\
\text { Mortgage } \\
\text { Banks }\end{array} \\
2\end{array}$} & $\begin{array}{r}\text { Credit } \\
\text { Unions \& } \\
\text { Coops. }\end{array}$ & $\begin{array}{l}\text { Money Mkt. } \\
\text { Mutual } \\
\text { Funds }\end{array}$ & $\begin{array}{r}\text { Other } \\
3 /\end{array}$ & & & & & & & \\
\hline Advanced Economies & 18 & & 1 & - & & - & & 3 & 15 & 2 & 3 & 2 & 2 & 2 & 2 & 3 & - \\
\hline \multicolumn{18}{|c|}{$\begin{array}{l}\text { Other Emerging Market and Developing } \\
\text { Countries }\end{array}$} \\
\hline Africa & 12 & 12 & 1 & 3 & & - & 4 & 1 & - & 3 & 1 & 1 & 1 & 1 & - & - & 1 \\
\hline Central and Eastern Europe & 13 & 13 & - & 2 & & 1 & 2 & 3 & 3 & - & - & - & - & - & - & - & - \\
\hline $\begin{array}{l}\text { Commonwealth of Independent } \\
\text { States }\end{array}$ & 7 & 7 & - & 1 & & - & - & - & - & - & - & - & - & - & - & - & - \\
\hline Developing Asia & 8 & 8 & 3 & 3 & & - & 3 & 2 & - & 2 & - & - & - & - & - & - & - \\
\hline Middle East & 2 & 2 & - & 1 & & - & - & - & - & 1 & - & - & - & - & - & - & - \\
\hline Western Hemisphere & 24 & 24 & - & 5 & & 1 & 9 & 6 & 3 & 11 & 2 & 3 & - & 1 & - & 3 & 4 \\
\hline Total & 84 & 84 & 5 & 15 & & 2 & 20 & 15 & 21 & 19 & 6 & 6 & 3 & 4 & 2 & 6 & 5 \\
\hline
\end{tabular}

Source: International Financial Statistics, Supplement on Monetary and Financial Statistics, Washington-IMF, December 2007.

1/ Including development, saving, postal, and export-import banks.

21 Other depository corporations allowing deposits from residents.

4/ Including issuers of asset-backed securities.

$5 /$ Includes leasing companies, financial dealers and brokers, and distributor companies.

6/ Including general deposit warehouses, guarantee corporations, real estate investment trusts, funding corporations, development funds, and asset management companies. 


\section{REVIEW OF TREATMENT OF DATA ISSUES IN STAFF REPORTS}

\section{Review of the sample of $\mathbf{5 0}$ staff reports finds that they generally include clear data adequacy assessments in the main report or in the SIA, albeit with a few exceptions. The three categories specified in the data guidance note are typically used. In 6 percent of cases there is no clear indication of whether data provision is adequate.}

\section{Most staff reports seem to assess appropriately the adequacy of data provision, though a minority of assessments seem to be more positive than warranted:}

- $\quad$ Based on the information presented in the staff report (including the SIA), ex post reviewers' assessment of data adequacy coincides with that of staff reports in 78 percent of cases. However, reviewers would consider data deficiencies in 10 percent of countries to be sufficiently serious as to warrant a characterization of "inadequate data" rather than "broadly adequate" (or unclear), and in another 10 percent to warrant "broadly adequate" instead of "adequate," suggesting a small potential upward bias in staff assessments. ${ }^{1}$ For example, in two post-conflict countries, the staff report characterized data as "broadly adequate" even though national accounts data were largely estimated, trade data missed key components of exports and imports, and serious weaknesses affected public debt and other fiscal data-elements which caused reviewers to consider that staff's analysis was "severely hampered in most areas central to surveillance," and thus that the criteria for an "inadequate" characterization were met. Similarly, for those countries where STA's Data Quality Assessment Framework (DQAF) ratings are available, staff's assessments of data adequacy for surveillance are found to be consistent with DQAF ratings in about 90 percent of cases, but upward bias also seems to exist in the rest of the cases, where assessments are more positive than comparable DQAF ratings.

- It is also difficult to reconcile the very infrequent description of data as "inadequate" with the large number of mission chiefs who report concerns about key data gaps or serious deficiencies (paragraph 5, main text). Indeed, close to 30 percent of survey respondents reported difficulty in choosing between the "broadly adequate" and "inadequate" characterizations, with none eventually choosing the "inadequate" characterization. Reasons for these choices included most prominently concern about the impact of the "inadequate" label on the Fund's ability to conclude the Article IV consultation (half the relevant respondents), alongside concern about the potential impact of the term on relations with the authorities and a sense that the term seemed too negative in the face of genuine capacity constraints.

\footnotetext{
${ }^{1}$ There is one case (out of the 50) where reviewers find that the staff assessment of "inadequate" is too negative.
} 
Staff reports' discussion of the implications of data deficiencies for surveillance is often weak. Existing guidance requires that these implications be discussed in the main text of the staff report in all cases where data are characterized as less than adequate. In practice, in about three quarters of these cases such discussion is absent or limited to noting that "data weaknesses hamper surveillance." For example, there may be no discussion of the implications of very outdated CPI weights for analyzing inflation figures; of the implications for fiscal analysis of large discrepancies between estimates of the fiscal deficit and financing data; or of the consequences of inadequate coverage of external trade data (as important categories of goods are omitted) for external sector analysis.

\section{Staff reports do not consistently propose remedial measures for major data shortcomings, and there is little sense of the authorities' response:}

- $\quad$ Existing guidance calls for a discussion of remedial measures ("in most cases...brief") in the main text of the staff report in all cases where data are characterized as less than adequate. In practice, staff reports propose remedial measures in only two thirds of these cases, and even in the SIA recommendations are often only partial or generic (a third of the cases).

- $\quad$ Existing guidance does not require a discussion of the authorities' stance on remedial measures, even in cases where data provision is considered clearly inadequate.

Consistently, where staff reports do include specific proposals these often reflect recommendations from technical assistance (TA) reports, with little evidence that the authorities' views, as elicited during the Article IV mission, have been incorporated. Although the survey suggests that discussions with authorities on data issues are often more intensive than reported in the staff report (about half the mission chiefs reported having had serious discussions with the authorities on data issues), about a third of the mission chiefs who saw key data gaps or serious deficiencies indicated that discussions of data issues were limited.

\section{In general, relevant details on major statistical issues are presented adequately in the} SIA, but — alongside discussions of implications of data deficiencies — there is room for improvement in coverage and focus. Reviewers generally find that SIAs provide adequate details on data issues in the traditional sectors (real, fiscal, monetary, external). However:

- The discussion does not necessarily reflect the severity of the issues, including their implications for surveillance. Reviewers find many cases where SIAs offer lengthy discussions of data issues of secondary significance. Just under 60 percent of mission chiefs were confident that only significant data deficiencies were listed in the SIA. A possible reason for this lies in the fact that area departments rely heavily for the drafting of the SIA on the Statistics Department (STA), which provides an expert view on data quality but is less well-placed than the country team to assess data 
adequacy for surveillance. Almost half the respondents to the survey reported that they relied primarily on STA for the SIA, either in full or for all except the opening summary assessment.

- In addition, the SIA generally does not cover financial sector data issues. This lack of coverage may reflect in part the fact that under current practice, only STA is asked to provide input to the SIA, so information gathered through FSAP missions is often omitted. 


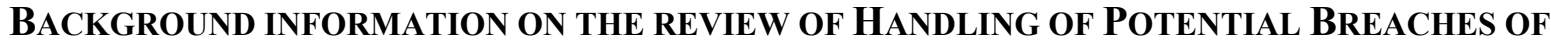 ARTICLE VIII, SECTION 5}

\section{A. Summary of cases of concern about potential breaches of Article VIII, Section 5}

The following table summarizes key facts about the eleven cases where staff had sustained concerns that the authorities were not sharing required data to the best of their ability.

\begin{tabular}{|c|c|c|c|c|c|c|}
\hline ID & $\begin{array}{l}\text { Types of } \\
\text { Data }\end{array}$ & $\begin{array}{l}\text { Type of } \\
\text { problem } 1 /\end{array}$ & $\begin{array}{l}\text { Concerns shared } \\
\text { with other } \\
\text { Departments? }\end{array}$ & $\begin{array}{l}\text { Board } \\
\text { informed of } \\
\text { staff concerns? }\end{array}$ & Status 2/ & $\begin{array}{l}\text { Timeframe } \\
\text { until } \\
\text { resolution, or } \\
\text { until 2/28/08 } \\
\text { if still open 3/ }\end{array}$ \\
\hline 1 & CPI & M & $\mathrm{Y}$ & $\mathrm{N}$ & $\mathrm{O}$ & $<1$ \\
\hline 2 & IIP & $\mathrm{N}$ & Y & Y & $\mathrm{C}$ & $2+$ \\
\hline 3 & CPI, fiscal & $\mathrm{L}$ & $\mathrm{N}$ & $\mathrm{N}$ & $\mathrm{C}$ & $2+$ \\
\hline 4 & $\begin{array}{l}\text { NDF } \\
\text { BOP, GDP, } \\
\text { fiscal, }\end{array}$ & $\mathrm{N}$ & Y & $\mathrm{N}$ & $\mathrm{C}$ & $<1$ \\
\hline 5 & prices & $\mathrm{L}$ & $\mathrm{Y}$ & Y & $\mathrm{O}$ & $2+$ \\
\hline 6 & IIP & $\mathrm{N}$ & Y & Y & $\mathrm{C}$ & $2+$ \\
\hline 7 & Reserves & $\mathrm{N}$ & Y & $\mathrm{Y}$ & $\mathrm{C}$ & $1+$ \\
\hline 8 & CPI & M & Y & $\mathrm{Y}$ & $\mathrm{O}$ & $2+$ \\
\hline 9 & $\begin{array}{l}\text { Reserves } \\
\text { Fiscal, } \\
\text { external }\end{array}$ & $\mathrm{L}$ & $\mathrm{N}$ & $\mathrm{N}$ & $\mathrm{O}$ & $1+$ \\
\hline 10 & debt & M & Y & $\mathrm{N}$ & $\mathrm{O}$ & $2+$ \\
\hline 11 & Reserves & M & Y & $\mathrm{Y}$ & $\mathrm{C}$ & $<1$ \\
\hline
\end{tabular}

1/ Types of data reporting problems are: non-provision of data (N); mis-provision,

i.e., provision of inaccurate data $(\mathrm{M})$; and late provision, i.e., providing data with excessively long lags (L).

2/ Status is either closed, i.e. resolved $(\mathrm{C})$, or is open and still being pursued $(\mathrm{O})$.

3/ Timeframe is either less than about one year $(<1)$; between one and two years $(1+)$; or more than two years $(2+)$.

\section{B. Phases in the Handling of Potential Breaches of Article VIII, Section 5}

Handling of these cases typically involves several phases. In a first phase, staff become aware of problems with data provision that may be unrelated to capacity, and take initial steps to follow up on the concerns - usually in the form of internal discussion on the nature of the issue and a strategy to address it. For five of the eleven cases, staff took less than a month to begin to follow up. In four cases staff had longstanding concerns about nonreporting (two cases), late reporting (one case), or misreporting of data (one case), but it is difficult to discern from the records when concerns about the member's willingness to provide data first arose. For two cases, concerns were not shared among departments, 
although staff made repeated efforts to obtain the data from the authorities, and one of these was resolved through the member providing timely and comprehensive data.

A second phase involves interdepartmental discussion to reach consensus on the nature of the concerns and next steps, including informing management. Except for the four cases where the first phase is less clear-cut, initial internal agreement on the nature of the issue and next steps was reached rather quickly (in less than a month). There were also cases where departments differed on next steps and management was asked to make the final decision. In one instance, staff pursued a case solely under the relevant SDDS procedures without realizing that the issue in question had potential Article VIII, Section 5 implications. This was an isolated case that subsequently informed the handling of two other cases.

Staff then engage the authorities to seek clarification, often repeatedly, and when applicable, propose steps to resolve potential breaches. Contact with authorities varied among the cases reviewed. Except for the four cases where the first phase is less clear cut, first contact started less than a month after initial concerns emerged (sometimes immediately e.g. during the mission), and there were also quick follow-ups after receiving responses from the authorities. But in some cases, contacts with the authorities on data provision largely coincided with Article IV consultations, which could lead to delays of more than a year (especially if the country is on a two-year consultation cycle). In three cases, there were a few additional contacts between the end of the mission and the scheduled Board discussion, usually aimed at resolution before the Board discussion. During the many rounds of interactions with the authorities, staff generally kept management informed on developments and internal discussions on next steps, particularly in cases where there were differences of views.

In all cases, the respective Executive Director's office was informed when there were formal contacts with the authorities, and in a few cases, staff actively sought assistance from the Executive Director's office (formally or informally) at various times during the process and reported positive results.

Management engaged directly with the authorities in only three or four cases, and its involvement occurred late in the process. Management's involvement also took various forms. In two cases, management engaged by meeting with the authorities. In another case, management wrote to the authorities requesting data (though not invoking the formal procedures), and in still another case, management wrote to the authorities urging better general cooperation with the Fund in surveillance without explicitly mentioning data problems.

Generally, reporting to the Board occurs in the context of Article IV consultations. One case which was resolved in between Article IV consultations was not reported to the Board, while another was discussed extensively on other occasions where the country was on the Board's 
agenda, as well as in the following Article IV report. Another resolved case was not reported because engagement had been continuous until resolution. In the two cases involving nonreporting of IIP data, the Board was explicitly informed about the potential breaches in successive Article IV staff reports. In two other cases, staff did not explicitly mention Article VIII.5, but did highlight concerns about possible data manipulation in the staff report, or alluded to non-cooperation in providing required data. In one case, staff informed the Board in an informal country matters session that the Article IV consultation could not be concluded in part because of data problems. Staff has not reported to the Board concerns with regard to the three remaining active cases because the process of engaging the authorities for clarification or cooperation is still underway. ${ }^{1 /}$

\section{Interpretation of the "understandings" applicable to the data under Article VIII, Section 5}

In two cases where issues arose in the interpretation of the "understandings" applicable to the data under Article VIII, Section 5, staff took a pragmatic approach focused on the degree of departure from internationally-accepted practice. In one pending case, staff believe that methodological changes reported by the member may run counter to certain principles set forth in the relevant internationally-accepted manual, and is discussing the changes with the authorities. In another case, staff determined that it was not in a position to conclude that the member's reporting of reserves data had been "inaccurate," because the problems - matters of asset classification, reconciliation of central bank trading and balance sheet data, and criteria for recognition of short-term funding - fell outside the scope of the general understandings applying to such data (and notably could not be resolved by reference to the high level principles embedded in the Reserves Template).

1/ In those cases, however, the Board was informed of the existence of data problems in staff reports. 